\title{
Predicting the Preventive Behaviors of Cutaneous Leishmaniasis in families with Children Under 10 Years, Applied the Precede Model
}

\begin{abstract}
Background and Objective: Cutaneous leishmaniasis is one of the endemic diseases in Iran and every year a large number of children under10years of age are infected with it. Therefore, the aim of this study was to investigate the preventive behavior of leishmaniasis based on the PRECEDE model in families with children under 10 years.

Materials and Methods: The present study is a cross sectional study that was performed on240Families with children under 10 years old in the Sankhast ward of North Khorasan province. The data collection tool was a researcher questionnaire that included demographic questions and structures of the questionnaire model (knowledge, attitude, reinforcing factor, and enabling factor). Sampling was performed in several steps. Data was entered into SPSS16 software using Kolmogorov-Smirnov test, one-way analysis of variance, independent t-test, correlation coefficient, multiple linear regressions.

Results: The highest mean a score was obtained by the reinforcing factor ( 24.3 \pm 22.80 ) and the lowest mean a score was obtained in the performance section $(48.46 \pm 15.66)$. The results of the regression model showed that knowledge (0.28), attitude (0.16), and enabling factors $(0.14)$ had the highest predictive power of mothers in controlling and preventing disease, respectively. Overall, the structures of the PRECEDE model predicted $21 \%$ of the variance of the preventive behavior of cutaneous leishmaniasis.

Conclusion: The PRECEDE model is a good theoretical framework for the prevention of leishmaniasis. Designing and implementing an educational program based on the PRECEDE model in the population at risk will be an effective step in controlling leishmaniasis. Because the prevalence of leishmaniasis is higher in rural areas, it is more important to consider the conditions of the rural people in order to implement the educational program.
\end{abstract}

Keywords: Cutaneous leishmaniasis, PRECEDE model, prevention, behaviors Paper Type: Research Article.

Citation (Vancouver): Jajarmi H, Gholian-Aval M, pourtaheri A, Esmaily H, Hosseini $\mathrm{H}$, Rajabzadeh R, Tehrani H. Predicting the Preventive Behaviors of Cutaneous Leishmaniasis in families with Children Under 10 Years, Applied the Precede Model. Iran J Health Educ Health Promot. Winter 2022;9(4):360-371.

> Citation (APA): Jajarmi H., Gholian-Aval M., pourtaheri A., Esmaily H., Hosseini H., Rajabzadeh R., Tehrani H. (Winter 2022). Predicting the Preventive Behaviors of Cutaneous Leishmaniasis in families with Children Under 10 Years, Applied the Precede Model. Iranian Journal of Health Education \& Health Promotion., 9(4),360-371.
Hosein Jajarmi

MSc, Department of Health Education and Health Promotion, Faculty of Health, Student Research Committee, Mashhad University of Medical Sciences, Iran.

Mahdi Gholian-Aval

Associated professor, Department of health education\& health promotion, Faculty of Health, Mashhad University of Medical Sciences, Mashhad, Iran

Asma pourtaheri

Ph.D. candidate, Department of Health Education and Health Promotion, Faculty of Health, Student Research Committee, Mashhad University of Medical Sciences, Iran

Habibollah Esmaily

Professor, Department Biostatistics, Social Determinants of Health research center, Mashhad University of Medical Sciences, Mashhad, Iran

Seyed Hamid Hosseini

Ph.D. of Health Education and Promotion. Vector-borne Diseases Research Center, North Khorasan University of Medical Sciences, Bojnurd, Iran.

Rezvan Rajabzadeh

Ph.D. of Epidemiology. Vector-borne Diseases Research Center, North Khorasan University of Medical Sciences, Bojnurd, Iran.

Hadi Tehrani

* Associated professor, Department of health education\& health promotion, Faculty of Health, Mashhad University of Medical Sciences, Mashhad, Iran. (Correspondence author) Tehranih@ mums.ac.ir

Received: 2021/08/10

Accepted: 2021/10/22

Doi: 10.52547/ijhehp.9.4.360 


\section{بيش بينى رفتارهاى بيشكَيرى كننده از ليشمانيوز جلدى در خانوادههاى داراى كودى} زير •ا سال، كاربردى از الكوى بوسيد ليد ليديد

\footnotetext{
حسين جاجرمى كارشناسى ارشد آموزش بهداشت و ارتقاى سلامت،

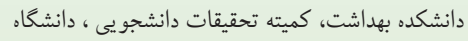
علو بِ شكى مشهد، مشهد، ايران. مهدى قليان اول دانشيار،كروه آموزش بهداشت و اروت ارتقاى سلامت، دانشكده بهداشت ، دانشكاء علوم يز شكى مشهد، مشهد،
}

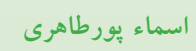
دانشجوى دكتراى تخصصى آموزش بهداشت و ارتقاى

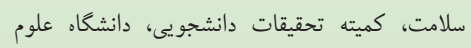
يز شكى مشهد، مشهد، ايران

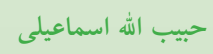
استاد، كروه ابيدميولوزى و آمار زيستى، مركز تحقيقات

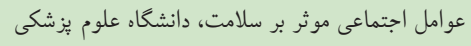
مشهد، مشهد، ايران.

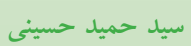
دكترى آموزش بهداشت و ارتقاء سلامت. مركز

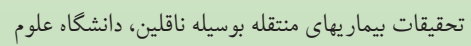
يز شكى خراسان شمالى، بجنورد، ايران.

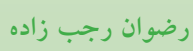
دكترى اييدميولوذى،مركز تحقيقات زاده بيماريهاى منتقله

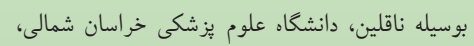
بجنورد، ايران

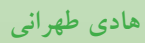
* * دانشيار ،كروه آموزش بهداشت و و ارتقاى سلامت،

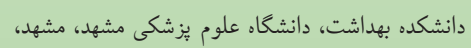
tehranih@mums.ac.ir

$$
\text { ايران. (نو يسنده مسئول): }
$$

تاريخ د ريافت: 9 | / /

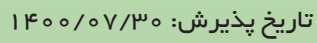

\section{جيكيده}

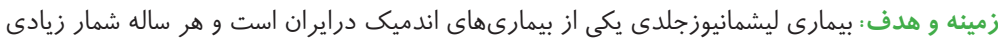

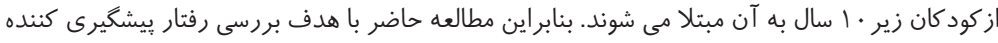

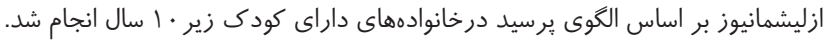

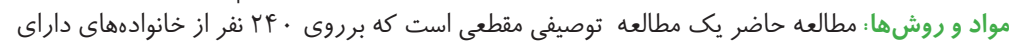

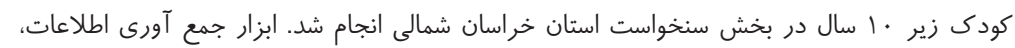

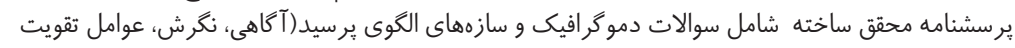

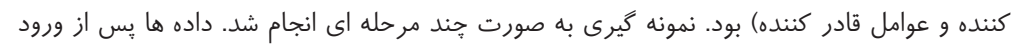

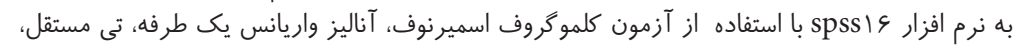

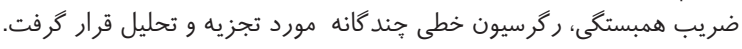

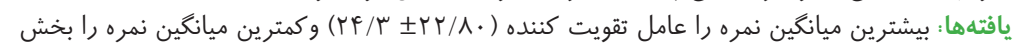

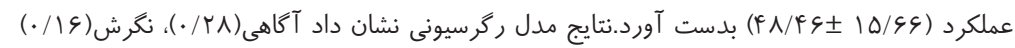

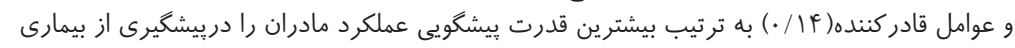

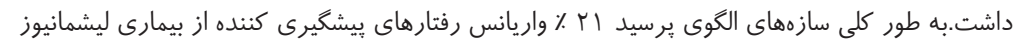
ا إيش بينى كردند.

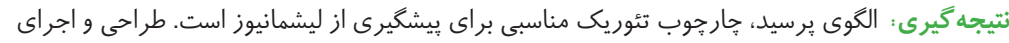

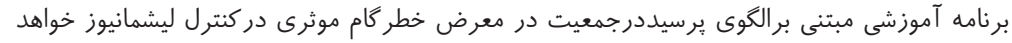

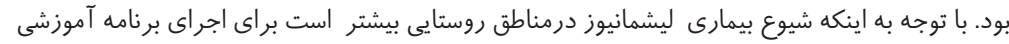

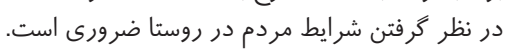

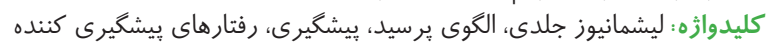

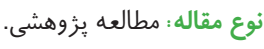

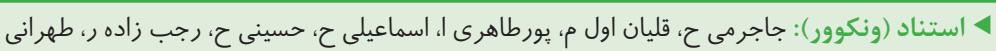

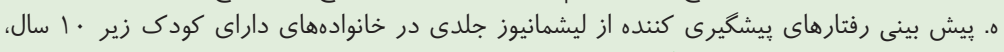

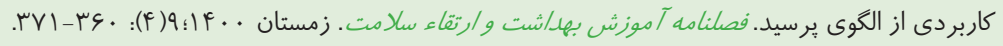

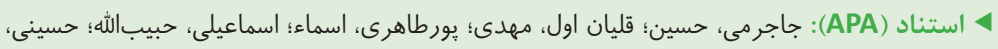

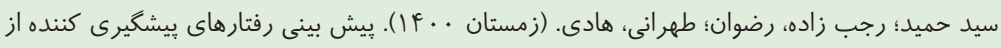

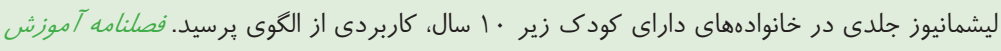

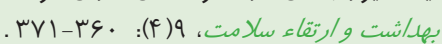


دامدارى است. نكهدارى دام در محل زندگى، وجود گونههاى متعدد جوندكان و هم جوارى با استانهايى كه ليشمانيوز جلدى در آنها دهاريا شيوع بالايى دارد، باعث افزايش شمار مبتلايان مى شود. با توجه

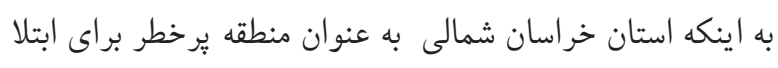

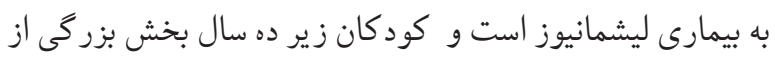

مبتلايان را شامل مى شود(^).

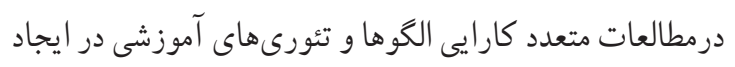

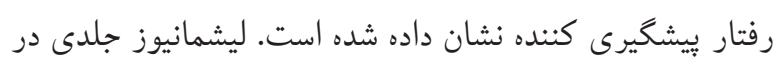

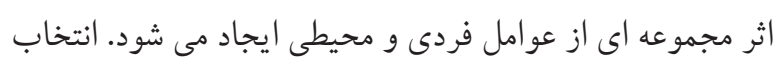

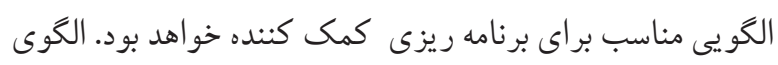

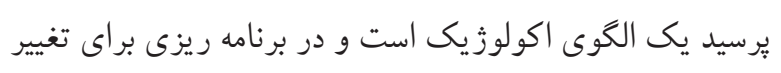

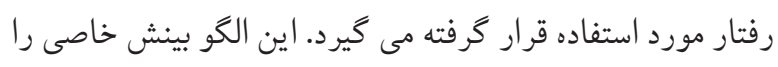
جهت ارزيابى ايجاد نموده و عوامل موثر در تغيير رفتار را تحليل

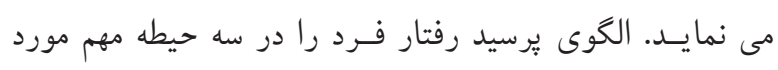

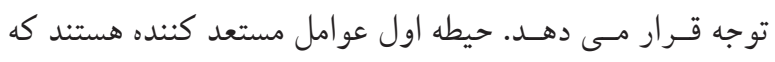

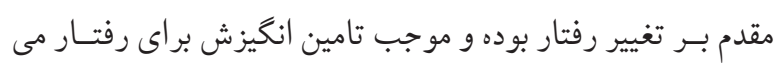

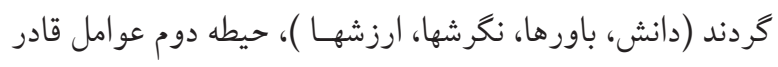

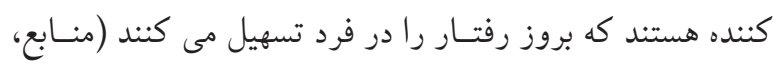

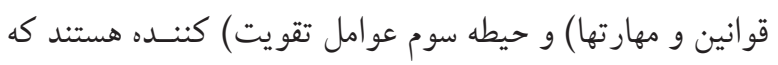

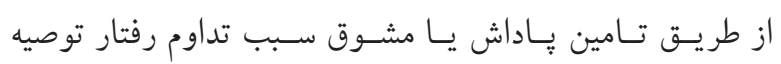

شده مى شـوند (خـانواده، همسالان، معلمان و....) (Y I ).

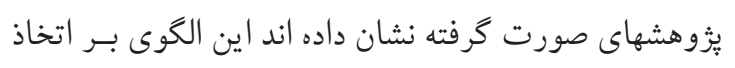

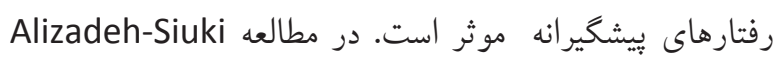

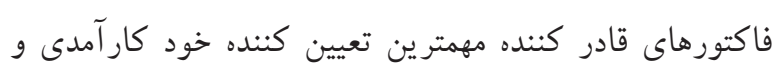

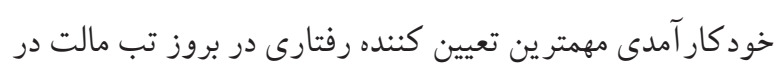

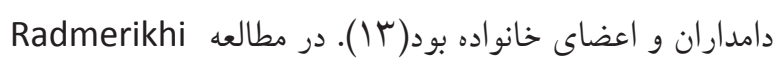

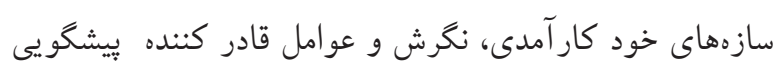
كننده رفتار تغذيه اى ييشخيرى كننده از بيمارى قلبى عروقى

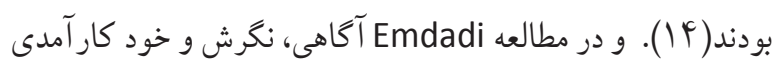

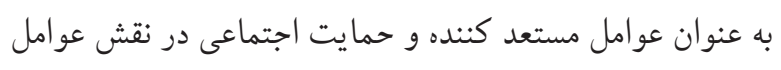

ليشمانيوز (Leishmaniasis) از بيمارى هاى مشترك بين انسان

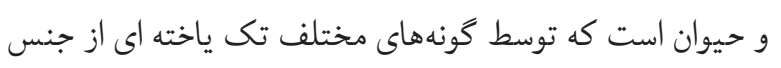

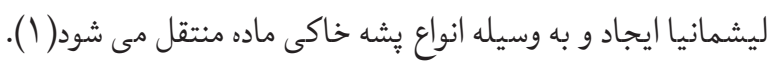
اين بيمارى به سه شكل جلدى (سالك)، احشايى (كالآزار) و جلدى -

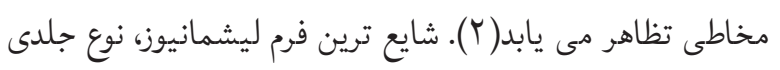
آن است كه به دو صورت خشك (شهرى) و مرطوب (روستايى)

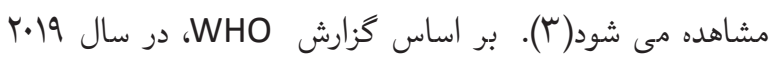

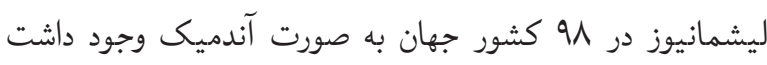

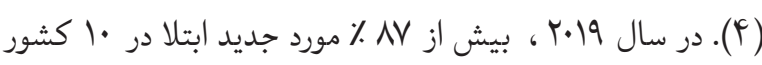
ايران، افغانستان، الجزاير، برزيل،كلمبيا،عراق،ليبى، پاكستان، ،سوريه، تانزانيا كزارش شده است(ه). درجهان، حدود با إميليون نفر مبتلا

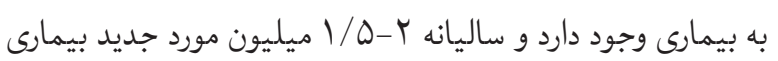

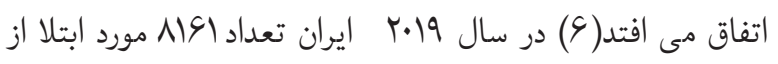

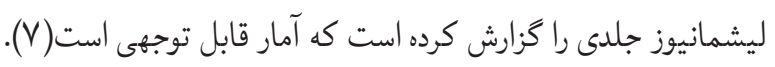
بيمارى ليشمانيوز در خراسان شمالى يك بيمارى اندميك است.

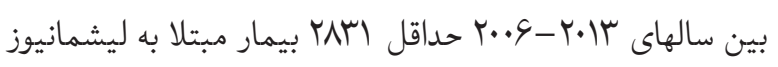
جلدى از مناطق مختلف استان گزارش شده است (^).

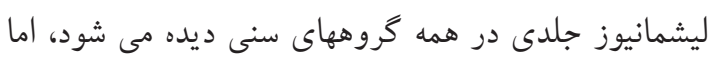

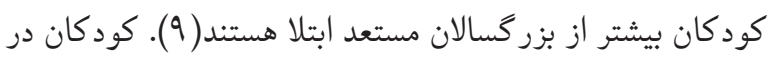
تماس بيشترى با پشه خاكى هستند، تشخيص بيمارى در آنها دشوار

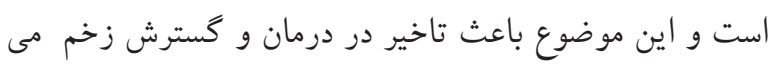
شود( • (1). كود كان براى درمان همكارى مناسبى ندارند و معمولا

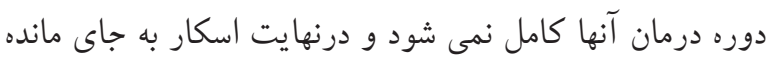

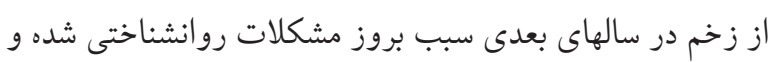

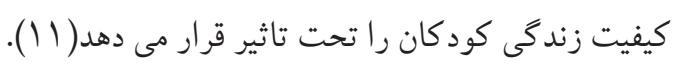

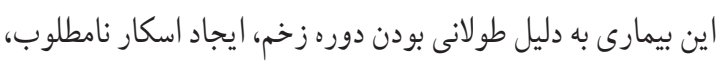

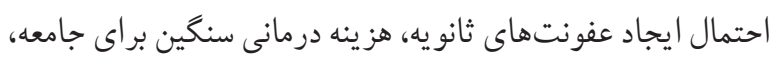
دوره طولانى درمان و عوارض ناشى از درمان با داروهاى موجوده،

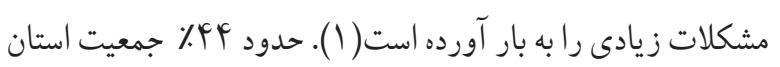
خراسان شمالى در مناطق روستايى سكونت دارند و شغل اصلى آنها 
فرزندان، سكونت حداقل 9 ماهه در بخش سنخواست و رضايت براى شركت در مطالعه به عنوان معيار ورود در نظر كرفته شد. در صورت ابتلاى كودى به ليشمانيوز جلدى مادر از مطالعه خارج

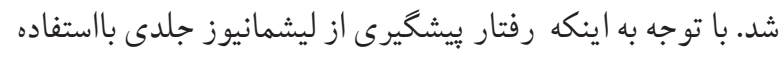

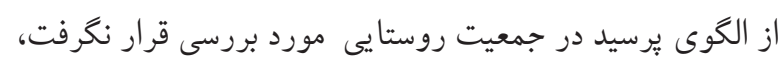

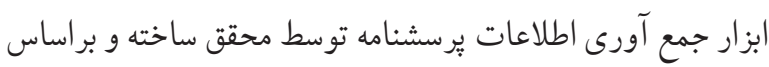

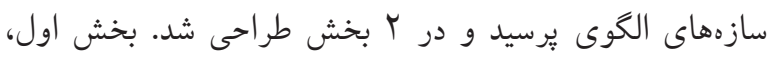
مشخصات دمو كرافيك (سن مادر، سن كودى، بعد خانوار و....) بود. بخش دوم، سازهاى الكوى برسيد شامل عو امل مستعد كننده (آكاهى ، نكرش)، عوامل قادر كننده و عوامل تقو يت كننده بوده.

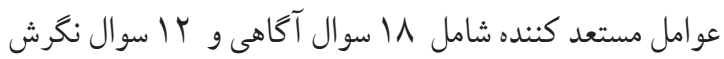
بود. سو الات آكاهى به صورت جهار كزينه اى طر احى شدند. ياسخ

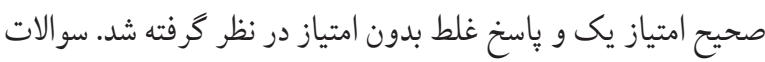

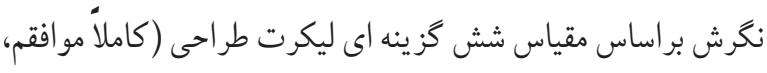

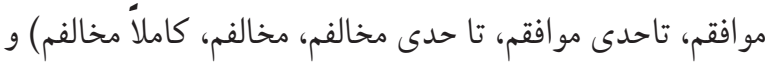

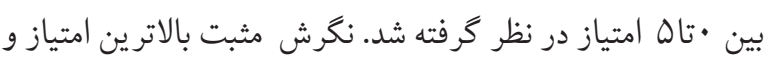

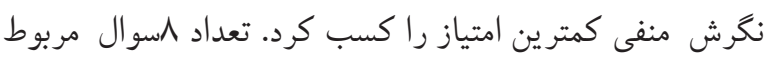

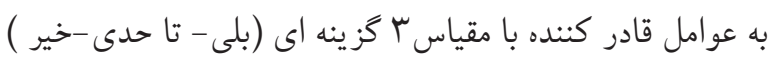

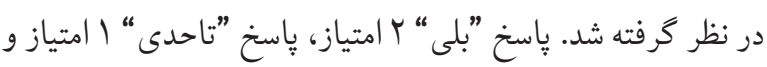

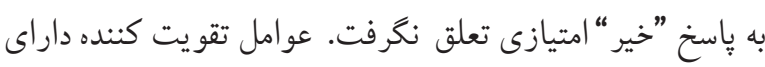

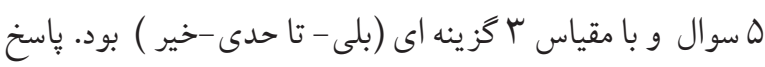

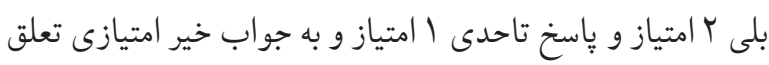

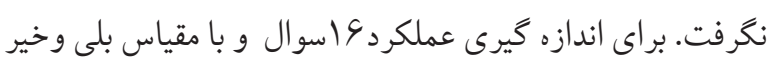

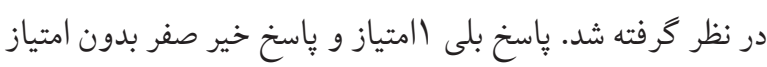

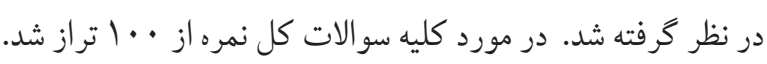
روايى صورى آزمون توسط متخصصين آموزش بهداشت و ارتقاى سلامت، حشره شناسى و إيدميولوزى انجام گرفت. نمره

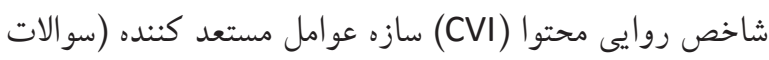

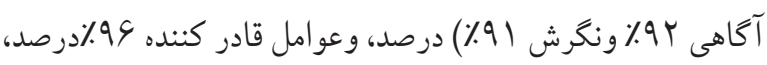

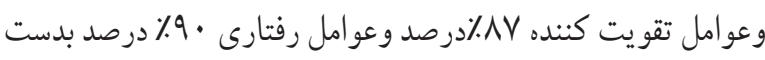

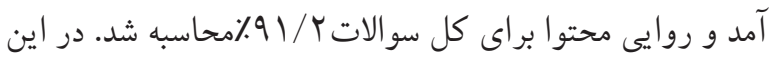

قادر كننده رفتار فعاليت فيزيكى را در زنان ميانسال ييش بينى

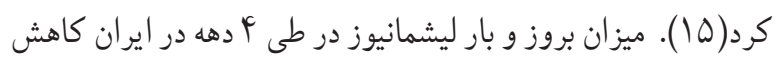

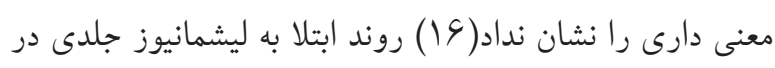

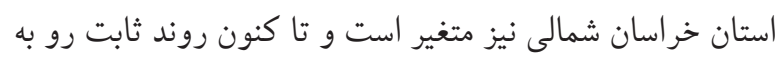
كاهش را تجربه نكرده است(IV) و ساليانه تعداد زيادى از كود كان

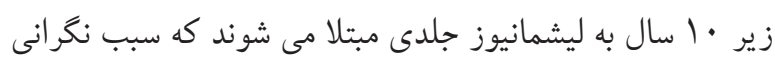

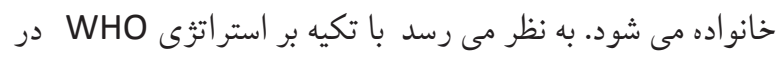

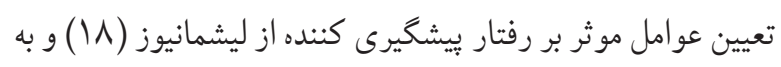

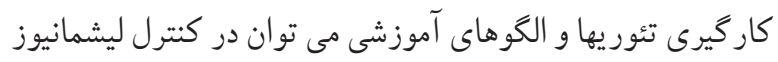

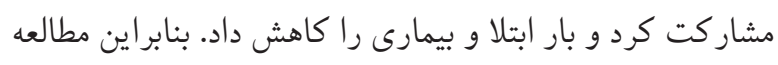
حاضربا هدف بررسى رفتار بيشگيرى كننده از ابتلا به ليشمانيوز

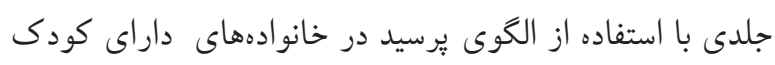

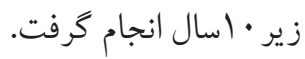
روش برروسى مطالعه حاضر يك مطالعه توصيفى مقطعى است. جمعيت مورد مطالعه را خانوادههاى داراى كودى زير •ا سال تشكيل دادند. اين مطع. مطالعه در بخش سنخواست[شهرستان جاجرم، استان خراسان شمالى)

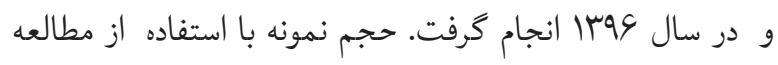

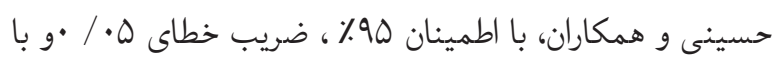

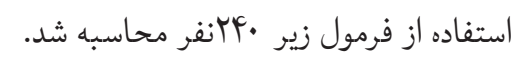

$$
\mathrm{n}=\frac{\left(\mathrm{z}_{1-\alpha / 2}\right)^{2} \mathrm{~S}^{2}}{(\mathrm{~d})^{2}}
$$

نمونه گيرى به صورت جند مرحله اى انجام گرفت. بدين صورت

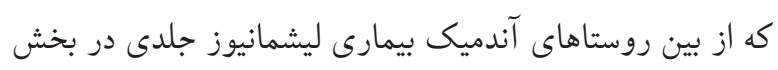

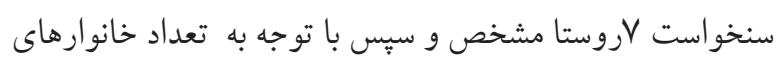

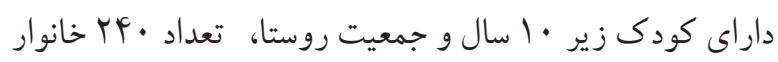

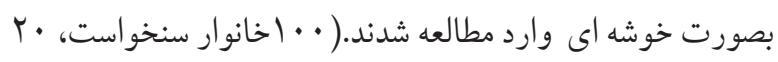

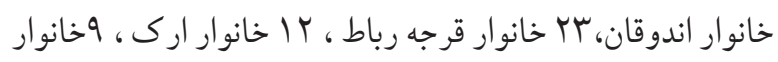
كلاته شور \&\& خانوار جربت و · ب خانو ار خراشا).

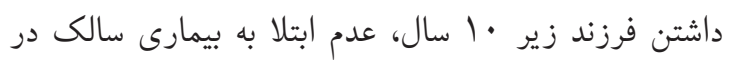


جدول ا: ميانكين و انحراف معيار متغيرهاى دموكَرافيك در خانوارهاى داراى كودى زير • • ال سال

\begin{tabular}{|c|c|c|c|}
\hline انحراف معيار / & ميانكين / تعداد & غير & \\
\hline$S / 0 S$ & $r r / 90$ & مادر & سن : \\
\hline$r / \mathbb{R} s$ & $f / 19$ & كودى & سن ك \\
\hline.$/ 99$ & $\varphi / 1$. & خانوار & بعد خ \\
\hline$\cdot / r V$ & $1 / \cdot 1$ & به ليشمانيوز & سابقه ابتلاى \\
\hline$r / \Lambda$ & 9 & بيسواد & \multirow{6}{*}{ تحصيلات مادر } \\
\hline$r 1 / V$ & $\Delta r$ & ابتدايى & \\
\hline $1 / / \mu$ & pq & راهنمايى & \\
\hline$r q / r$ & $9 F$ & دييلم & \\
\hline$r / \Delta$ & 4 & فوق دييلم & \\
\hline $1 F / 0$ & ro & كارشناسى & \\
\hline $9 \Delta / \wedge$ & $r \mu$. & خانه دار & \multirow{2}{*}{ شغل مادر } \\
\hline$r / r$ & 1. & كارمند & \\
\hline$V / I$ & IV & بيسواد & \multirow{7}{*}{ تحصيلات پِدر } \\
\hline$r Y / q$ & $\Delta \Delta$ & ابتدايى & \\
\hline$r \cdot / \kappa^{q}$ & $v^{\mu}$ & راهنمايى & \\
\hline$r s / \mu$ & sr & ديبلم & \\
\hline$s / \Gamma$ & 10 & فوق ديبلم & \\
\hline$r / 9$ & 11 & كارشناسى & \\
\hline$r / \tau$ & 4 & كارشناسى ارشد & \\
\hline $1 r / 9$. & ri & كارمند & \multirow{4}{*}{ شغل بدر } \\
\hline$r s / V$ & $11 r$ & كارگر & \\
\hline$r v / q$. & 91 & آزاد & \\
\hline$r / \Delta$ & 9 & ساير & \\
\hline $9 r / 1$ & rrI & بلى & \multirow{2}{*}{ سابقه ابتلا } \\
\hline$V / q$ & 19 & خير & \\
\hline $1 / \pi$ & $r$ & كولر كازى & \multirow{4}{*}{ نور مايشى منزيل } \\
\hline$\Lambda \Delta / \wedge$ & $r \cdot 4$ & كولر آبى & \\
\hline $1 . /$ & $r^{r}$ & קهنكه & \\
\hline$r / 9$ & $\checkmark$ & ن ندارد & \\
\hline
\end{tabular}

در جدول شماره r ارتباط بين سازههاى الكوى يرسيد و

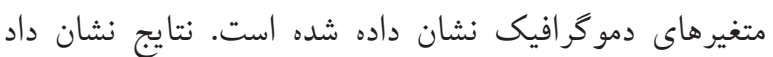
بين ميانكين نمره آكاهى گِدران بيسواد و داراى تحصيلات
مطالعه نسبت روايى محتوا (CVR) براى سازه عو امل مستعد كننده

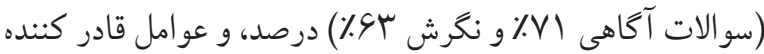

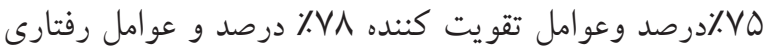

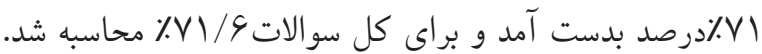

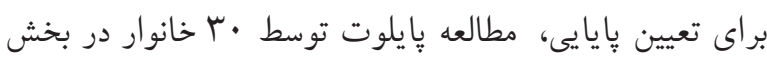

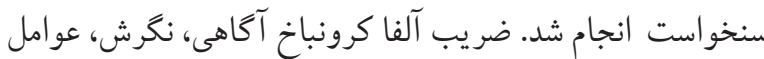

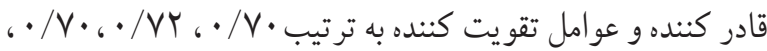

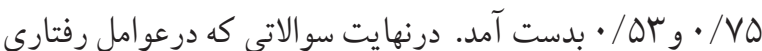
باعث كاهش آلفاى شده بودند حذف شد. براى تجزيه و تحليل

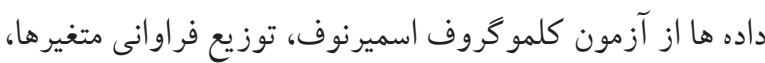
ميانخين، انحراف معيار، آناليز واريانس يك طرفه، تى مستقل،

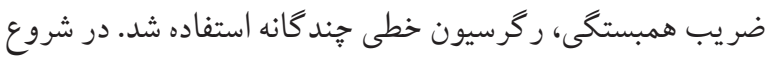

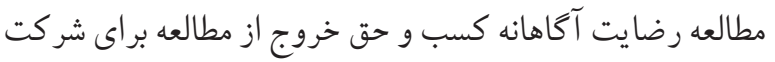

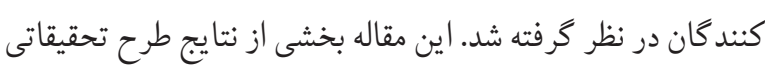

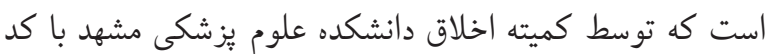
IR.MUMS. REC. 1396. 221 نتايج

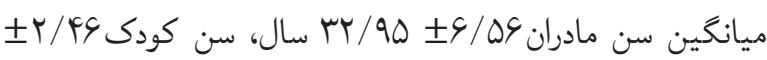

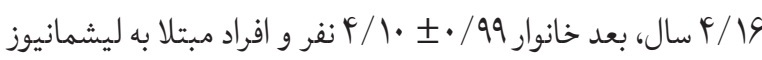

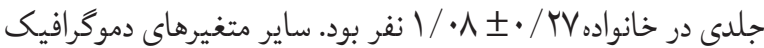
در جدول شمارها نشان داده شده است. ميانگين نمره (تراز شده از

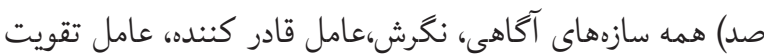
كننده و عملكرد كمتر از •لم بوده است. بيشترين ميانخين نمره

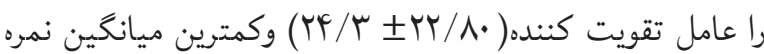

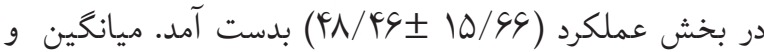

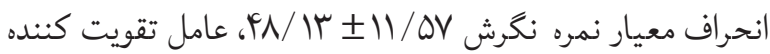

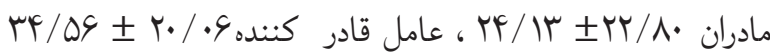

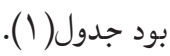


سابقه ابتلا به بيمارى درخانواده ارتباط معنى دار آمارى وجود .

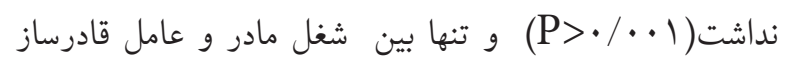

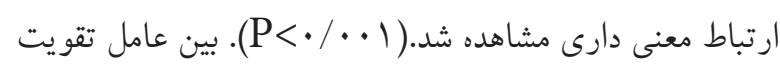
كننده و سطح تحصيلات يدر و مادر، شغل پيدر و مادر، سابقه ابتلا

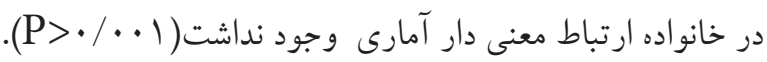

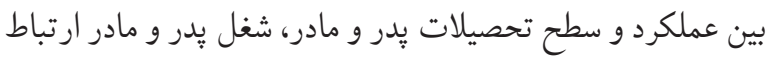

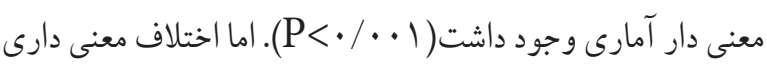

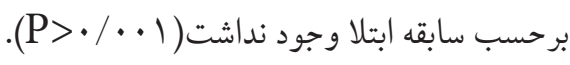

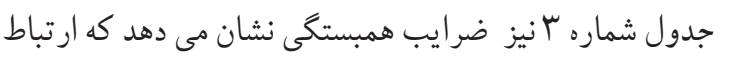

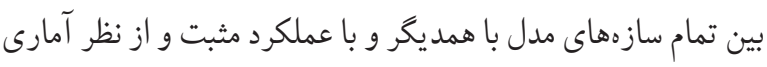
معنى دار بود ( جدول شماره ب).
ابتدايى( (Y/ ا

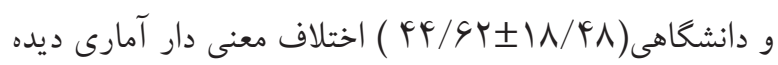

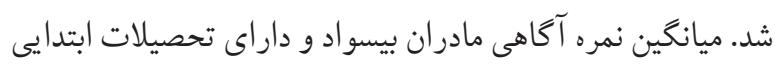

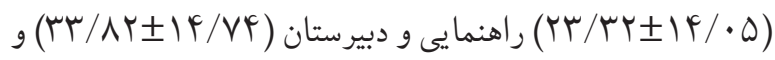
دانشخاهى( وجود داشت. هم جنين بين شغل يدر و مادر، سابقه ابتلادر خانو اده

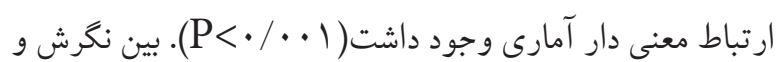

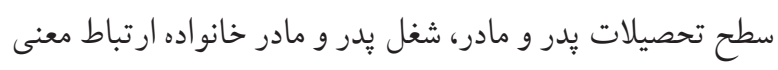

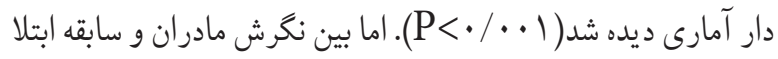

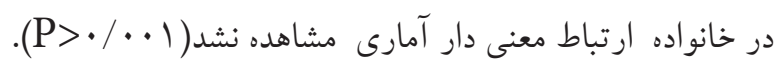

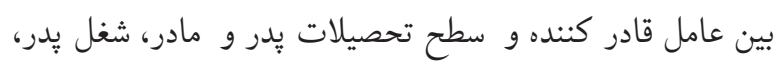

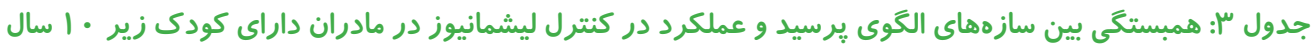

\begin{tabular}{|c|c|c|c|c|c|c|}
\hline عملكرد & عوامل تقويت كننده & عوامل قادر كننده & ن نغرش & آكاهى & & متغير \\
\hline$\cdot / \pi 9 \Delta$ & $\cdot / r \cdot r$ &.$/ 19 \wedge$ &.$/ 4 F q$ & 1 & ضريب همبستىى & \multirow{2}{*}{ آكاهى } \\
\hline $\mathrm{P}<\cdot / \cdot \cdot 1$ &.$/ .1$ &.$/ 19$ & $\mathrm{P}<\cdot / \cdot \cdot 1$ & & P-value & \\
\hline · & $\cdot / r \mid F$ & . / TYF & 1 & & ضريب همبستىى & \multirow{2}{*}{ 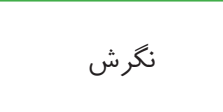 } \\
\hline $\mathrm{P}<\cdot / \cdot \cdot 1$ &.$/ \cdot 1$ & $\mathrm{P}<\cdot / \cdot \cdot 1$ & & & P-value & \\
\hline$\cdot / r \Delta \Lambda$ & $\cdot / \mu \cdot \varphi$ & 1 & & & ضريب همبستىى & \multirow{2}{*}{ عوامل قادر كننده } \\
\hline $\mathrm{P}<\cdot / \cdot \cdot 1$ & $\mathrm{P}<\cdot / \cdot \cdot 1$ & & & & P-value & \\
\hline$\cdot / r F Y$ & 1 & & & & ضريب همبستكى & \multirow{2}{*}{ عوامل تقويت كننده } \\
\hline $\mathrm{P}<\cdot / \cdots 1$ & & & & & P-value & \\
\hline
\end{tabular}

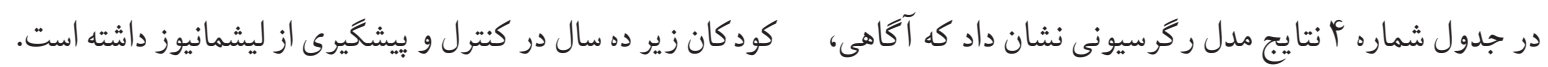

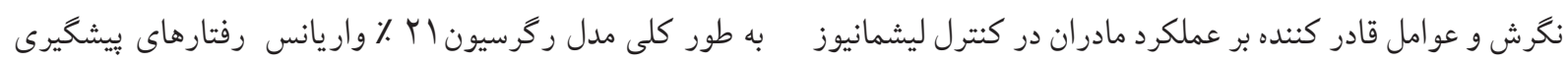

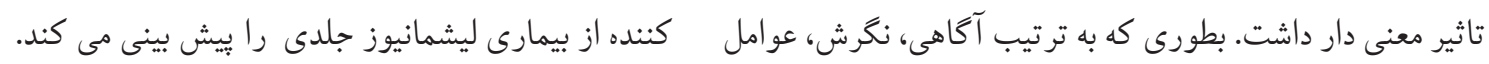

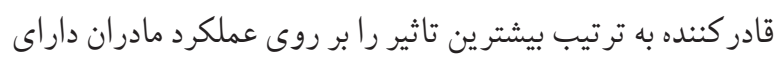

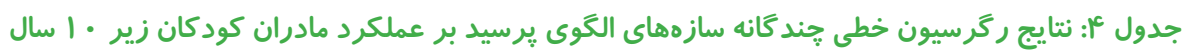

\begin{tabular}{|c|c|c|c|c|c|}
\hline$p$-value & $\begin{array}{c}\text { آماره آزمون } \\
\text { (t) }\end{array}$ & ضريب ركرسيون استاندارد & $\begin{array}{c}\text { خطاى معيار } \\
\text { SE }\end{array}$ & ضريب ركرسيون & متغير هاى بيش بينى كننده \\
\hline $\mathrm{P}<\cdot / \cdot \cdot 1$ & $\varphi / \mu$. & $\cdot / T \Lambda$ & .1 .9 & $\cdot /$ KS & آكاهى \\
\hline.$/ .11$ & $r / \mu \wedge$ & .119 &.$/ .9$ & $\cdot / r 1$ & نكرش \\
\hline$\cdot / \cdot r \mid$ & $r / \mu r$ &.$/ 1 F$ &.$/ .0$ &.$/ 11$ & عوامل قادر كننده \\
\hline .1 .94 & $1 / \wedge \Delta$ &.$/ 11$ &.$/ \cdot F r$ & $\cdot / \cdot \vee \wedge$ & عوامل تقويت كننده \\
\hline
\end{tabular}




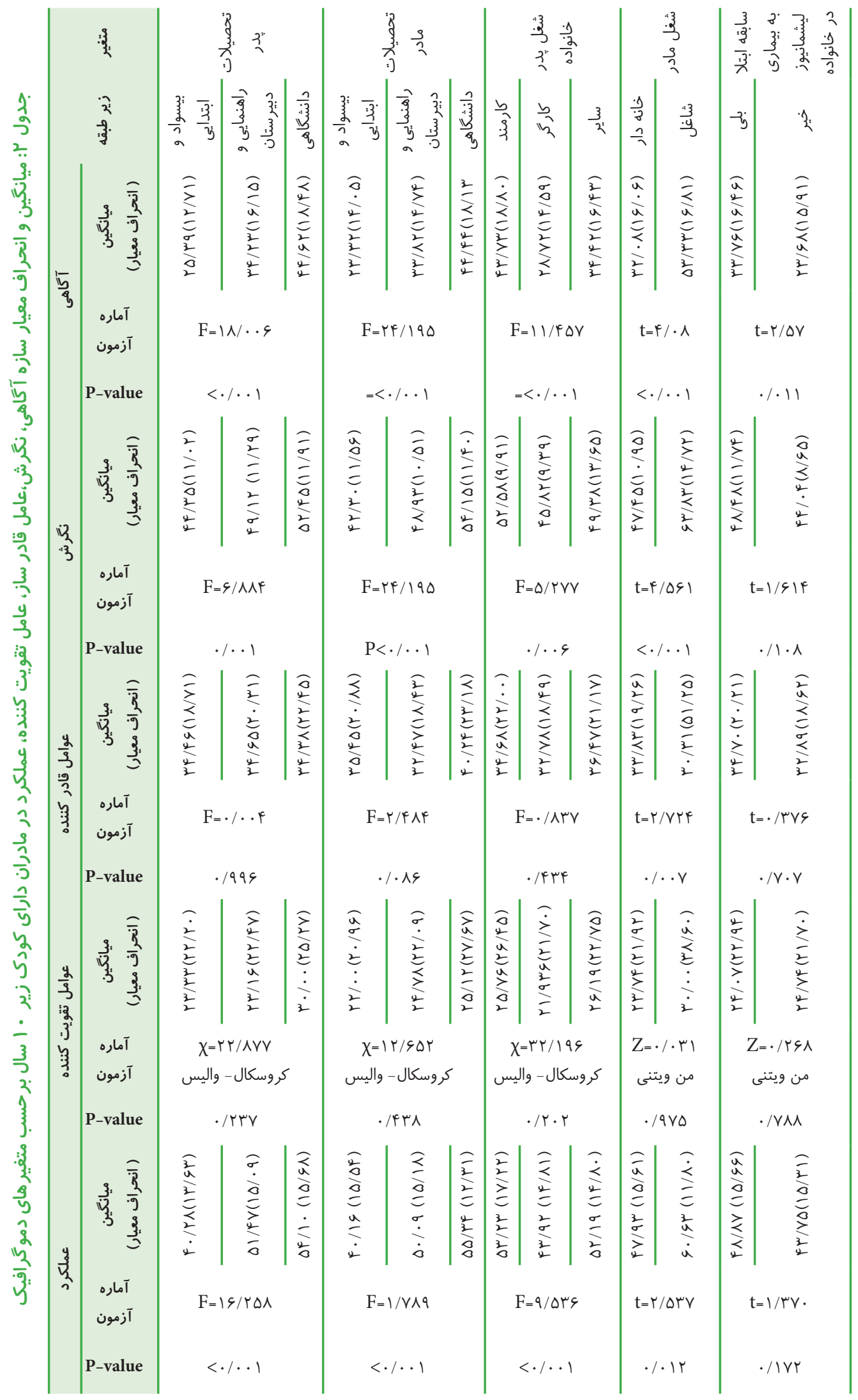


بحث و نتيجاه كيرى

ليشمانيوز جلدى در بسيارى از مناطق كشور از جمله استان خراسان

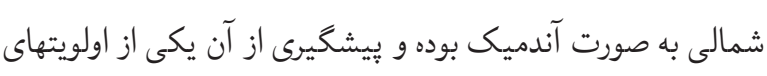

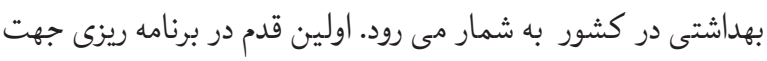

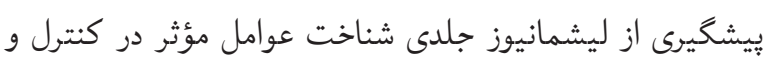

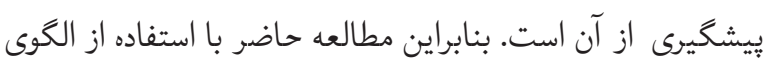

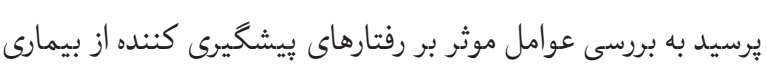

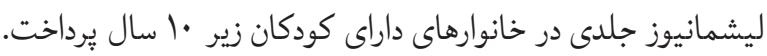

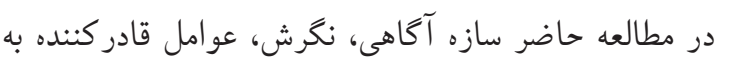
ترتيب بيشترين تاثير را بر رفتار بيشكيرى كننده از ليشمانيوز

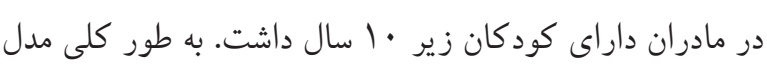

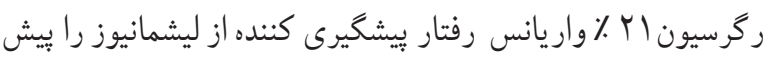
بينى كرد و عو امل تقويت كننده بر عملكرد مادران تاثير كذار نبود.

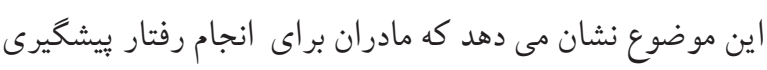
به آكاهى، نكرش و امكانات و تجهيزات لازم نياز دمان دارند. اين نتايج

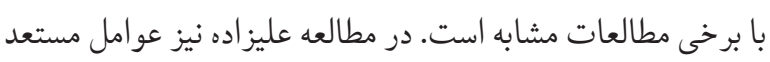

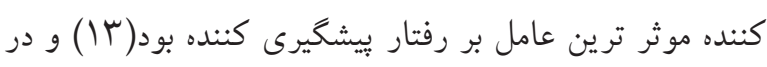
مطالعه Radmerikhi آكاهى بالاترين تاثير را بر رفتار داشت( (If)

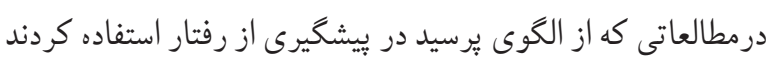

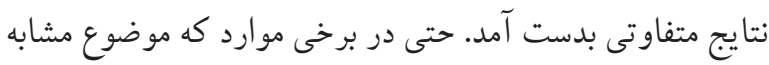

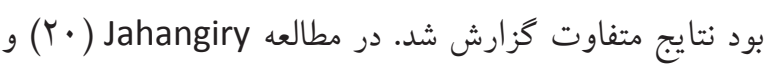
حشمتى( آT) عو امل تقويت كننده و در مطالعه على اكبرى عوامل

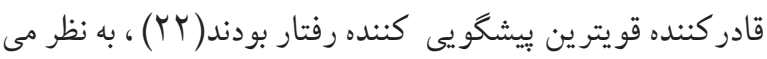

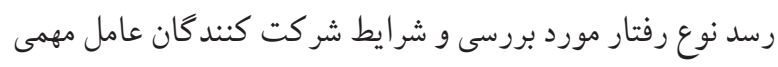

$$
\text { در ايجاد نتايج متفاوت باشد. }
$$

در مطالعه حاضر مادران از آكاهى لازم براى رفتار بيشكيرى بـاني

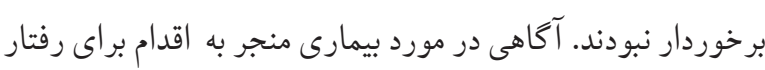

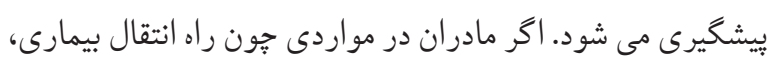

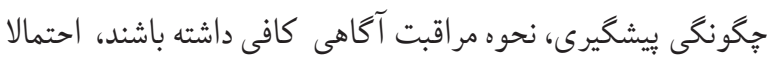

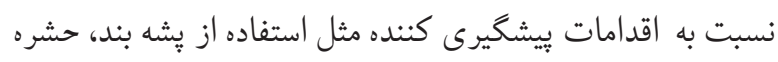
كش و شروع به موقع درمان نكرش مثبتى به دست خواهند آورد.
با توجه به اينكه متغيرهاى شغل پدر و مادر و تحصيلات يدر

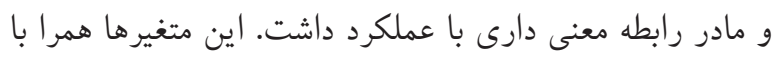

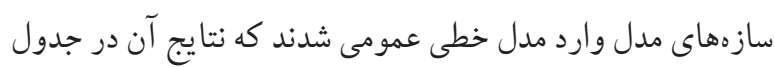

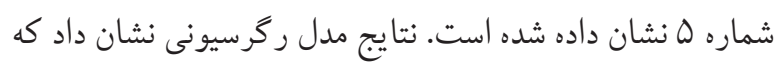

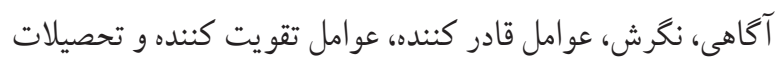
يدر بر عملكرد مادران در كنترل ليشمانيوز جلدى تاثير معنى دار

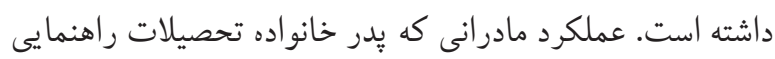

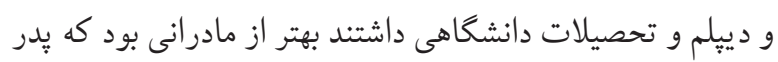

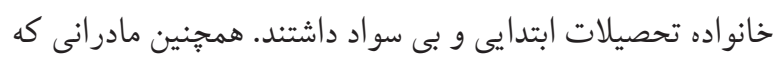

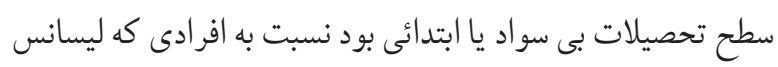

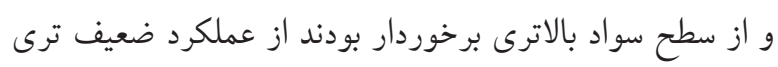

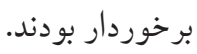
جدول ه: نتايج مدل خطى عمومى در تاثير سازههاى الثَوى ير سيد و

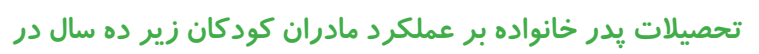
كنترل سالك

\begin{tabular}{|c|c|c|c|c|}
\hline p-value & $\begin{array}{l}\text { آماره آزمون } \\
\text { (t) }\end{array}$ & خطاى & ضريب & متغير \\
\hline$\cdot / \cdot f$ & $r / q F$ & $\cdot / \cdot \Delta \Delta$ &.$/ 194$ & آ آكاهى \\
\hline.$/ 19$ & $r / 19$ & $\cdot / \cdot r$ &.$/ .0$ & 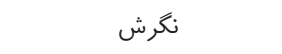 \\
\hline$\cdot / \cdot r$ & $r / 99$ & $\cdot / \cdot r$ & . / fru & عوامل قادر كننده \\
\hline$\cdot|\cdot|+1$ & $r / . \Delta$ & .1 .9 &.$/ 1 \mu r$ & عوامل تقويت كننده \\
\hline$\cdot / \cdots 1$ & - & $\cdot / \vee \wedge$ & $-r / S$ & تحصيلات بدر خانواده \\
\hline$\cdot / \cdots \Delta$ & $-r / \wedge \Delta$ & . / & $-1 / 1$ & تحصيلات يدر خانواده \\
\hline . / FVS & $-\cdot / V I F$ & $\cdot / 099$ & $-\cdot / q r$ & $\begin{array}{c}\text { تحصيلات يدر خانواده } \\
\text { (راهنمائى) }\end{array}$ \\
\hline.$/ 190$ & $-1 /$ rq1 & .1099 & $-\cdot / \wedge r$ & تحصيلات يدر خانواده \\
\hline$\cdot / \cdot \Delta V$ & $-1 / 911$ & - MSP & $-1 / 49$ & تحصيلات پِدر خانواده (فوق \\
\hline
\end{tabular}


تحصيلات رابطه معنى دارى داشت(Yq). عليزاده و حجارى نيز

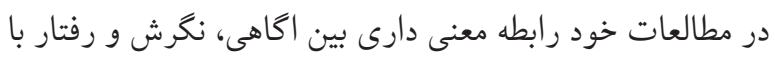

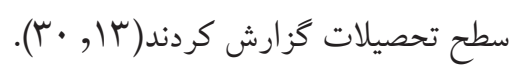

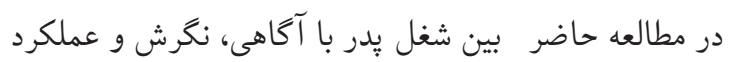

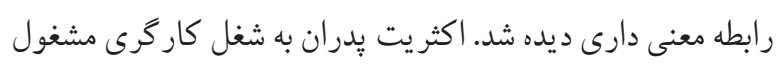

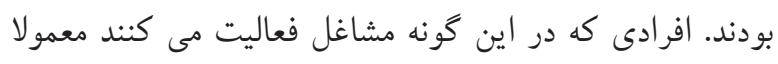
سطح تحصيلات پايين ترى دارند و ساعات بيشترى مشغول كار

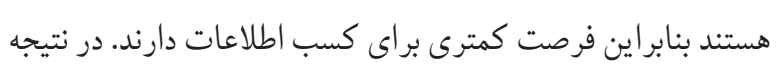
آكاهى، نكرش و عملكرد ضعيف ترى نسبت به كارمندان و ساير ين

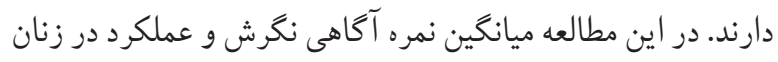

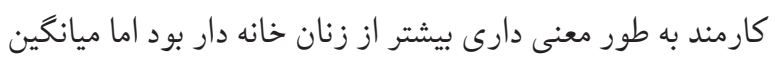

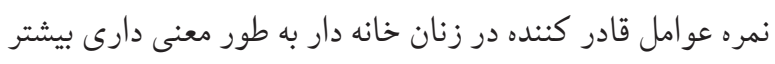

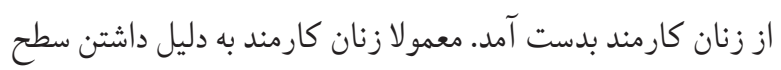
تحصيلات بالاتر آكاهى، نكرش و عملكرد بهترى نسبت به زنان

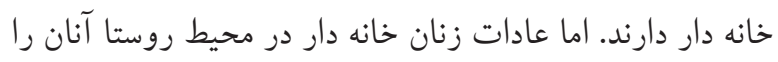

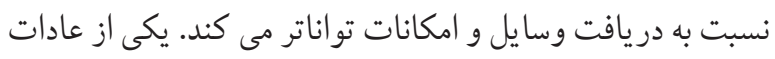
زنان خانه دار در محيط روستا تشكيل دورهمىهاى متعدد است.

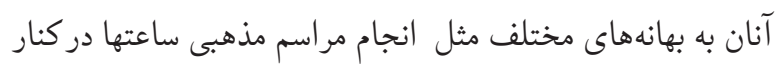

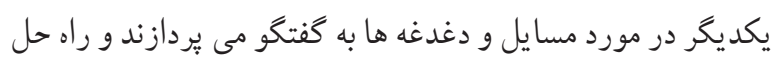

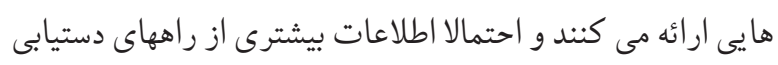

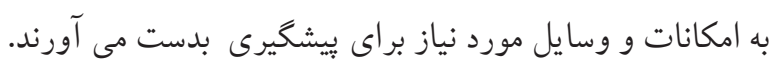

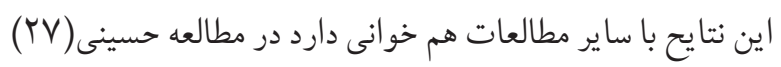

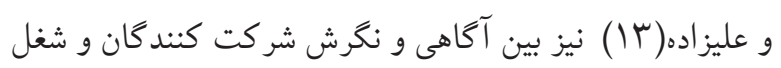
آنها رابطه معنى دارى ديده شد.

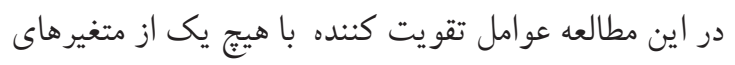

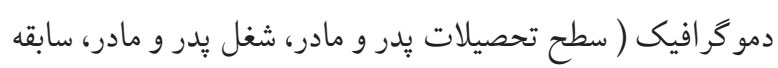

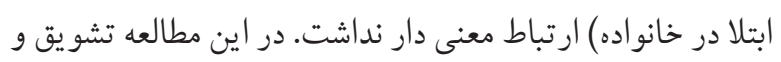

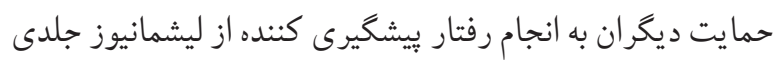

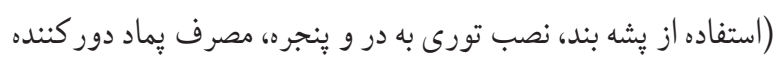

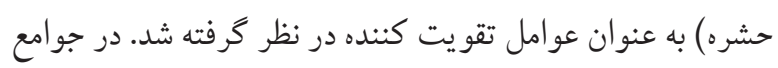

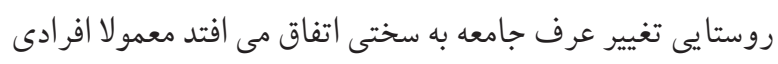

دور اينجا وجود امكانات لازم، مثل محلى براى خريد يشه بند و حشره

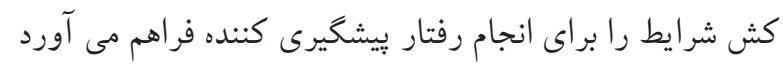

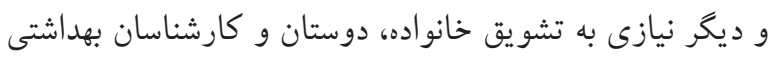

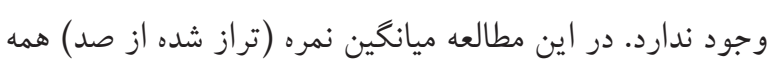

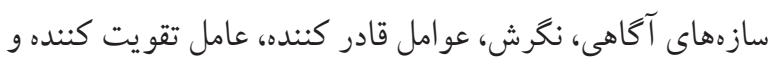

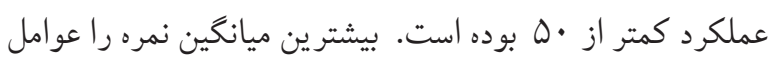
تقويت كننده و كمترين ميانگين نمره در بخش عملكرد بدست

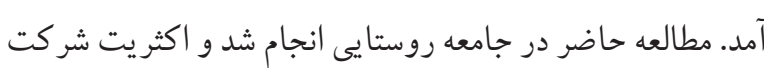

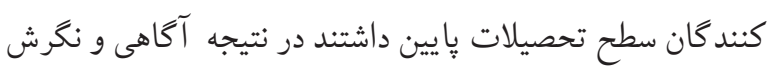
آنها يايين بود، در حقيقت نداشتن آكاهى به معنى نداشتن يِيش نياز

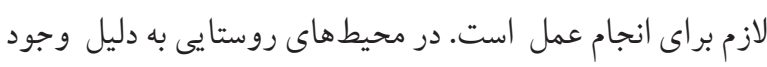

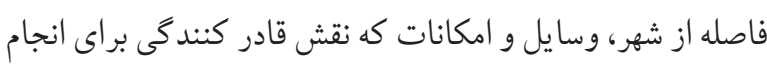

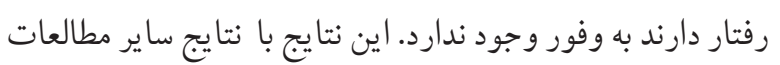

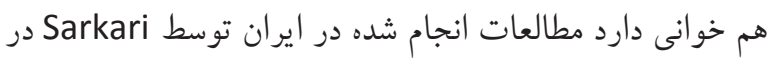

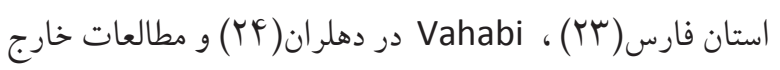

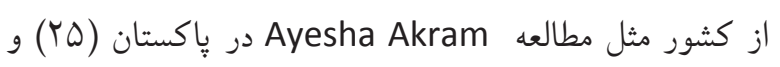
Tamiru

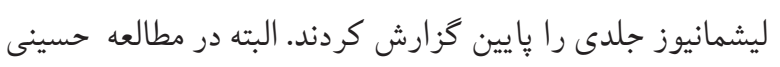

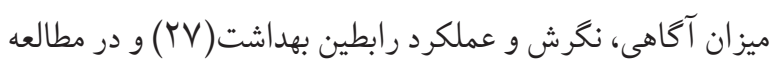

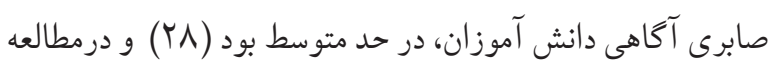

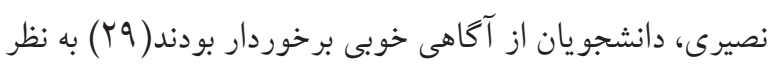

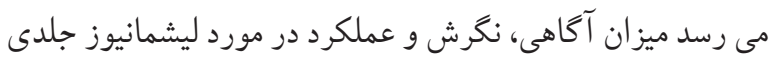
در ميان محصلين و دانشجويان و افرادى كه در سيستم بهداشت دميز مشغول به كار هستند نسبت به عموم جامعه وضعيت بهترى دارد.

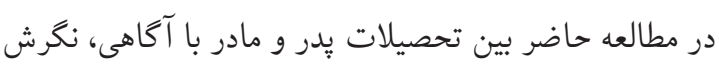

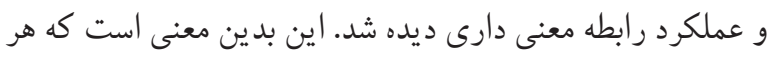

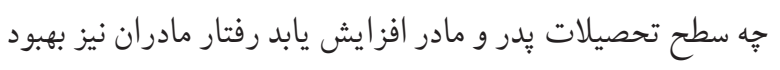
خو اهد يافت. به طورى كه بدران و مادران تحصيل كرده ميانكين

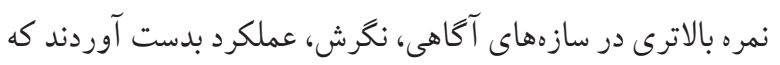

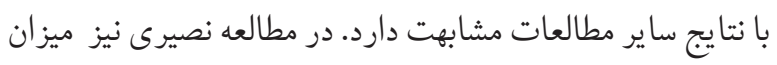

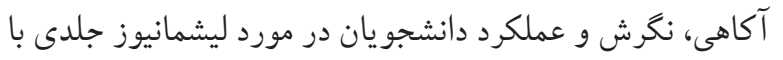


كه اطلاعات به صورت محرمانه باقى خو اهد ماند. انتخاب مادران

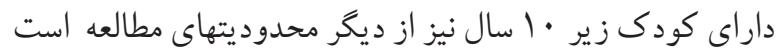

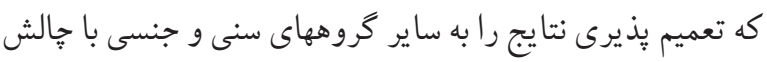

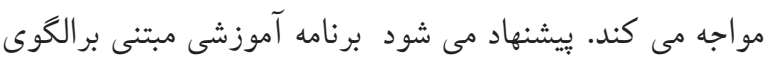

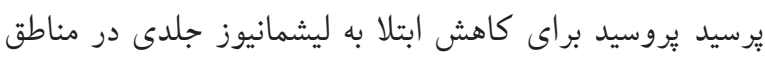

$$
\text { روستايى انجام كيرد. }
$$

نتيجنه گيرى: در مطالعه حاضر آكاهى، نكرش(عوامل مستعد كننده)

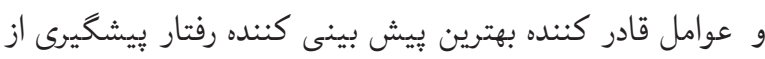
بيمارى ليشمانيوز جلدى در زنان داراى كودى زير ·لا سال بودند.

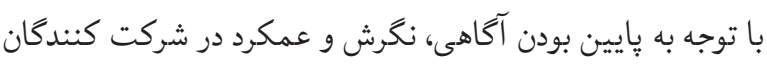

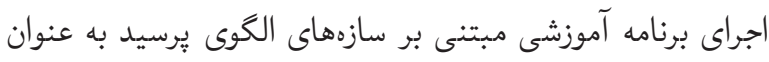
راهنمايى مناسب در يبشكيرى از بيمارى كمك كننده خواهد بود.

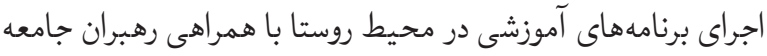

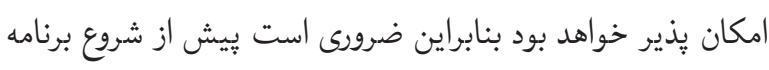

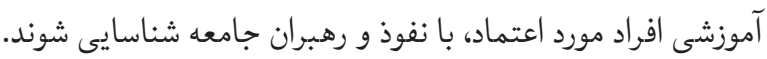

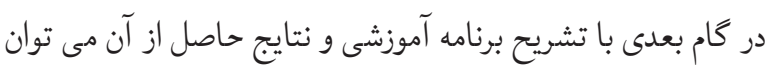

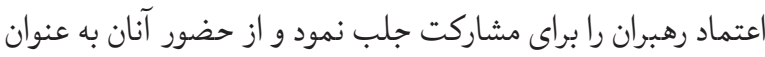
ييشخامان برنامه بهره برد. با ايجاد نقش تقويت كنندكى مناسب

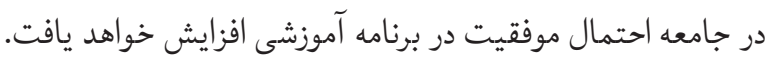

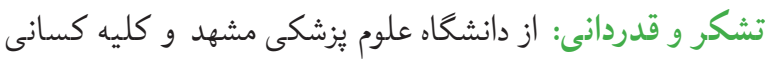
كه در اين يُوهش مارا يارى كردند قدردانى مى گردد.

\section{References}

1. Ghodsi M, Maheri $M$, Joveini $H$, Rakhshani $M H$, Mehri A. Designing and evaluating educational intervention to improve preventive behavior against Cutaneous Leishmaniasis in endemic areas in Iran. Osong public health and research perspectives. 2019;10(4):253. https://doi.org/10.24171/j.phrp.2019.10.4.09 PMid:31497498 PMCid:PMC6711717

2. Sabzevari S, Teshnizi SH, Shokri A, Bahrami F, Kouhestani F. Cutaneous leishmaniasis in Iran: A systematic review and meta-analysis. Microbial pathogenesis. 2021:104721. https://doi.org/10.1016/j.micpath.2020.104721 PMid:33539962

3. Sabzevari S, Mohebali M, Hashemi A. Cutaneous and visceral leishmaniasis: parasites, vectors and
كه داراى ويزگى خاصى هستند و يا افراد با نفوذ مثل كدخدا يا

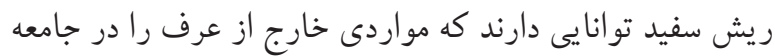
ترويج دهند و ديخران را به انجام عملى تشويق كنند. بنابر اين نتيجه

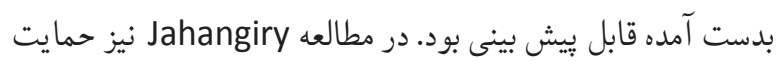

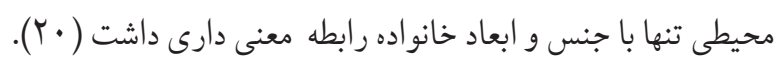

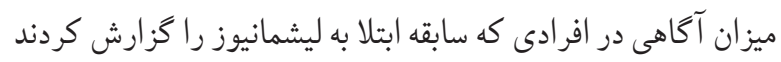

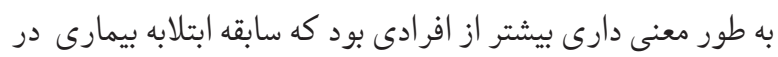

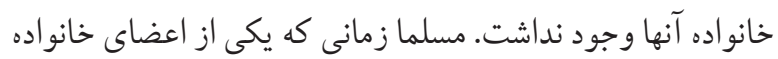

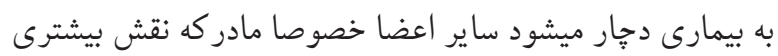
در مراقبت ايفا مى كند اطلاعات بيشترى در مورد بيمارى، نحوه

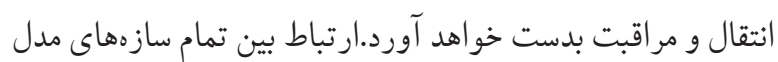

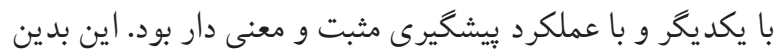

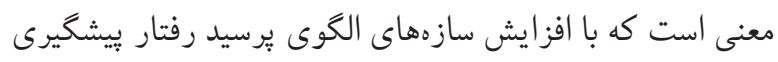
از ليشمانيوز نيز در مادران افزايش مى يايد. مطالعات مشابه نيز

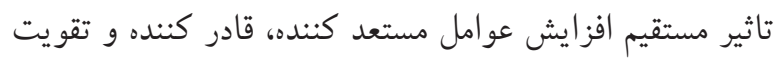

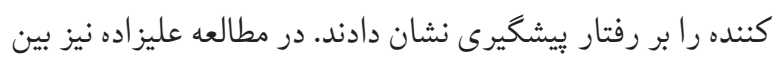
سازههاى و رفتار رابطه معنى دارى ديده شد( آ ).

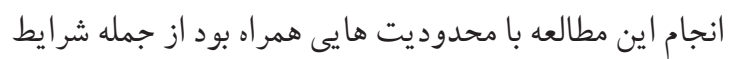
خاص فرهنگى حاكم در محيط روستا احتمال دريافت ياسخ هاى لناي نادرست به علت ترس از افشا شدن اطلاعات را افزايش مى دم داد.

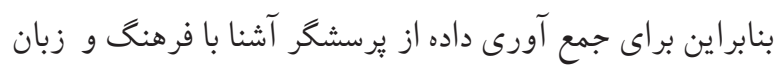

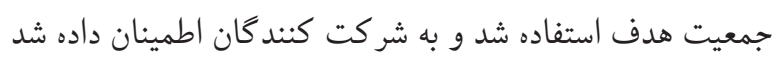

reservoir hosts in endemic foci of North Khorasan, Northeastern Iran-a Narrative Review. Journal of Medical Microbiology and Infectious Diseases. 2020;8(2):40-4. https://doi.org/10.29252/JoMMID.8.2.40

4. Postigo JAR. Leishmaniasis in the world health organization eastern mediterranean region. International journal of antimicrobial agents. 2010;36:S62-S5. https://doi.org/10.1016/j.ijantimicag.2010.06.023 PMid:20728317

5. World Health Organization LFS, WHO, 2019. https://www. who.int/news-room/fact-sheets/detail/leishmaniasis. 20 May 2021.

6. Piroozi B, Moradi G, Alinia C, Mohamadi P, Gouya MM, Nabavi M, et al. Incidence, burden, and trend of cutaneous 
leishmaniasis over four decades in Iran. Iranian Journal of Public Health. 2019;48(Supple 1):28-35..

7. Bi K, Chen Y, Zhao S, Kuang Y, John Wu C-H. Current visceral leishmaniasis research: a research review to inspire future study. BioMed research international. 2018;2018 https://doi .org/10.1155/2018/9872095 PMid:30105272 PMCid:PMC6076917

8. Rajabzadeh R, Arzamani K, Shoraka HR, Riyhani H. Epidemiological survey and geographical distribution of cutaneous Leishmaniasis in North Khorasan province, 2006-2013. International Journal of Epidemiologic Research. 2015;2(4):197-203.

9. Agrawal S, Khandelwal K, Bumb RA, Oghumu S, Salotra P, Satoskar AR. Pediatric cutaneous leishmaniasis in an endemic region in India. The American journal of tropical medicine and hygiene. 2014;91(5):901-4. https://doi.org/10.4269/ajtm h.13-0737 PMid:25294618 PMCid:PMC4228883

10. Gupta M. Cutaneous leishmaniasis in children: A case series. Indian Journal of Paediatric Dermatology. 2018;19(1):37. https://doi.org/10.4103/ijpd.IJPD_148_16

11. Turan E, Kandemir H, Yeşilova Y, Ekinci S, Tanrıkulu $O$, Kandemir SB, et al. Assessment of psychiatric morbidity and quality of life in children and adolescents with cutaneous leishmaniasis and their parents. Advances in Dermatology and Allergology/ Post py Dermatologii i Alergologii. 2015;32(5):344. https://doi.org/10.5114/pdia.2015.54744 PMid:26759542 PMCid:PMC4692819

12. shiani $m$, Jalili $z$, shojaeizadeh $d$. The Effect of Education Based on the Precede-Proceed Model on the Mental Health of Middle -aged Women referred to Municipal Health Houses of Tehran. Iranian Journal of Health Education and Health Promotion. 2020;8(4):309-23.. https://doi.org/10.29252/ijhehp.8.4.309

13. Alizadeh-Siuki H, Tehrani $H$, Gholian-Aval M, Ebrahimipour $\mathrm{H}$, Vahedian-Shahroodi M. Behavioral determinants of brucellosis incidence among stockbreeders and their family members in rural area based on PRECEDE model. Journal of Education and Health Promotion. 2020;9. https://doi.org/10.4103/jehp.jehp_635_19 PMid:32953898 PMCid:PMC7482639

14. Radmerikhi S, Tabatabaei SVA, Jahani Y, Mohseni M. Predicting effective factors on eating behaviors in the prevention of cardiovascular disease based on the PRECEDE model. Electronic physician. 2017;9(12):5894. h tt p s : / / d o i . org / $10.19082 / 5894$ PMid:29560139 PMCid:PMC5843413

15. Emdadi S, Hazavehie SMM, Soltanian A, Bashirian S, Moghadam RH. Predictive factors of regular physical activity among middle-aged women in west of Iran, Hamadan: application of PRECEDE model. Journal of research in health sciences. 2015;15(4):244-9.

16. Piroozi B, Moradi G, Alinia C, Mohamadi P, Gouya MM, Nabavi M, et al. Incidence, burden, and trend of cutaneous leishmaniasis over four decades in Iran. Iranian Journal of Public Health. 2019;48(Supple 1):28-35.

17. Norouzinezhad F, Ghaffari F, Norouzinejad A, Kaveh F, Gouya MM. Cutaneous leishmaniasis in Iran: results from an epidemiological study in urban and rural provinces. Asian Pacific journal of tropical biomedicine. 2016;6(7):614-9. https://doi.org/10.1016/j.apjtb.2016.05.005

18. Ejov M, Dagne D. Strategic framework for leishmaniasis control in the WHO European Region 2014-2020. 2014.

19. Glanz K, Bishop DB. The role of behavioral science theory in development and implementation of public health interventions. Annual review of public health. 2010;31:399-418. https://doi.org/10.1146/annurev. $\mathrm{pub|h}$ e a | th. 0128809.103604 PMid:20070207

20. Jahangiry L, Khazaee-Pool M, Mahdavi B, Ponnet K, Sarbakhsh P. Preventive factors related to brucellosis among rural population using the PRECEDE model: an application of path analysis. Tropical animal health and production. 2019;51(2):419-28. https://doi.org/10.1007/s11250-018-1708-2 PMid:30203266

21. Heshmati $H$, Behnampour N, Homaei E, Khajavi S. Predictors of fruit and vegetable consumption among female high school students based on PRECEDE model. Iranian Journal of Health Education and Health Promotion. 2014;1(4):5-14.

22. Aliakbari F MF, Rabiei L. Predictors of Self care in patiant understanding hemodialysis: an application of the PREDEDE model. journal of clinical nursing and midwifery. 2020;9(2):634-41.

23. Sarkari B, Qasem A, Shafaf MR. Knowledge, attitude, and practices related to cutaneous leishmaniasis in an endemic focus of cutaneous leishmaniasis, Southern Iran. Asian Pacific journal of tropical biomedicine. 2014;4(7):566-9. https://doi.org/10.12980/APJTB.4.2014C744 PMid:25183278 PMCid:PMC4032832

24. Vahabi A, Rassi Y, Oshaghi MA, Vahabi B, Rafizadeh S, Sayyad S. First survey on knowledge, Attitude and practice about cutaneous leishmaniasis among dwellers of Musian district, Dehloran County, Southwestern of Iran, 2011. Life Sci J. 2013;10(12):864-8.

25. Akram A, Khan HAA, Qadir A, Sabir AM. A crosssectional survey of knowledge, attitude and practices related to cutaneous leishmaniasis and sand flies in Punjab, Pakistan. PloS one. 2015;10(6):e0130929. https://doi.org/10.1371/journal.pone.0130929 PMid:26090870 PMCid:PMC4474799 
26. Tamiru HF, Mashalla YJ, Mohammed R, Tshweneagae GT. Cutaneous leishmaniasis a neglected tropical disease: community knowledge, attitude and practices in an endemic area, Northwest Ethiopia. BMC infectious diseases. 2019;19(1):1-10. https://doi.org/10.1186/s12879-019-4506-1 PMid:31619180 PMCid:PMC6796443

27. Hosseini SH AM, Shirabadi R , Arzamani K, Rajabzadeh R. The knowledge, attitude and practice of "Health-Go betweenes" Esfarayen country about cutaneousleishmaniasis disease in 2013. Journal of North Khorasan University of Medical sciences. 2015;7(4):735-43. https://doi.org/10.29252/jnkums.7.4.735

28.SaberiS,ZamaniA, MotamediN, NilforoushzadehMA, Jaffary $\mathrm{F}$, Rahimi E, et al. The knowledge, attitude, and prevention practices of students regarding cutaneous leishmaniasis in the hyperendemic region of the Shahid Babaie Airbase. Vector-Borne and Zoonotic Diseases. 2012;12(4):306-9. https://doi .org/10.1089/vbz.2010.0259 PMid:22022818

29. Nasiri Z ME, Rasaa SF, Jahanaifard E,, NabganSh EZ. A crosssectional study of the knowledge, attitude and practice of female students of Ahvaz Jundishapur University of Medical Sciences about cutaneous Leishmaniasis. Journal of Preventive Medicine. 2020;7(2):53-62. https://doi.org/10.29252/jpm.7.2.62

30. Hajari A SM, Afrooghi S, Fadaei Nobari R, Abaspoor Najafabadi R. Using the Precede-Proceed Model in Needs Assessment for the Prevention of Brucellosis in Rural Areas of Isfahan, Iran. Armaghane-danesh. 2016;21(4):395409. 